\title{
Prevalensi dan karakteristik supernumerary teeth pada anak usia 13-15 tahun di Makassar (The prevalence and characteristics of supernumerary teeth for children of 13-15 years old in Makassar)
}

\author{
${ }^{1}$ Asmawati, ${ }^{2}$ Bahruddin Thalib, ${ }^{3}$ Nurul Mutmainnah \\ ${ }^{1}$ Bagian Oral Biologi \\ ${ }^{2}$ Bagian Prostodonsia \\ ${ }^{3}$ Mahasiswa tahap profesi \\ Fakultas Kedokteran Gigi Universitas Hasanuddin \\ Makassar, Indonesia
}

\begin{abstract}
Supernumerary teeth is an abnormality in the form of increasing amount of teeth more than the normal amount, that is more than twenty twenty in the decidui dentition or thirty two in the permanent dentition. The objective of the present study was to investigate the prevalence and characteristics of supernumerary teeth of 13-15 year old children in Makassar. This descriptive study involved 13-15 year old children who were present during the oral examination in 14 junior high schools in Makassar. This cross-sectional study employed random sampling method. This study found 24 supernumerary teeth which yield a prevalence of $0.6 \%$. The prevalence among male was higher than among female (M:F of 2.1:1). The greatest proportion of supernumerary teeth was found in the maxillary anterior region consisting of single supernumerary teeth (90.9\%) and multiple supernumerary (9.1\%). The prevalence of characteristic sample based on their site of supernumerary teeth is mesiodens (58.3\%) and lateral incisor (41.7\%). Out of the 24 supernumerary teeth, $93.8 \%$ erupted and $4.2 \%$ partial erupted. The prevalence of characteristic sample based on their morphology is conical (83.4\%), tubercular (8.3\%), and supplementale (8.3\%). This study concluded that the prevalence of supernumerary teeth for children of 13-15 years old in Makassar was found higher among male (ratio M:F of 2.1:1) and they are most frequently located in the maxilla. Most cases presented only single supernumerary and in multiple cases the mesiodens region is predominant, with the conical shape is the commonest morphology.

Key words: supernumerary teeth, the children of 13-15 years old, mesiodens
\end{abstract}

\begin{abstract}
ABSTRAK
Supernumerary teeth atau gigi lebih merupakan suatu kelainan jumlah gigi berupa bertambahnya gigi dari jumlah normalnya, yaitu lebih dari 20 pada gigi sulung atau lebih dari 32 pada gigi permanen, dan dapat ditemukan di semua bagian lengkung gigi. Penelitian ini ditujukan untuk mendeskripsikan prevalensi dan karakteristik supernumerary teeth pada anak usia 13-15 tahun di Makassar. Penelitian deskriptif ini melibatkan semua anak usia 13-15 tahun di Makassar yang hadir saat pemeriksaan yang dilakukan di 14 sekolah menengah pertama di Makassar, dengan menggunakan pendekatan cross sectional study dan metode multistage random sampling. Hasilnya menunjukkan 24 supernumerary teeth (prevalensi 0,6\%), dan rasio laki-laki:perempuan adalah 2,1:1. Proporsi terbesar supernumerary teeth ditemukan di daerah anterior rahang atas. Dari jumlah tersebut, single supernumerary 90,9\% dan multiple supernumerary $9,1 \%$. Berdasarkan lokasinya, supernumerary teeth dengan jenis mesiodens 58,3\% dan jenis lateral 41,7\%. Sebanyak $93,8 \%$ yang erupsi sempurna dan erupsi sebagian 4,2\%. Berdasarkan keadaan morfologi, bentuk conical 83,4\%, tubercular 8,3\%, dan supplementale 8,3\%. Disimpulkan bahwa prevalensi supernumerary teeth pada anak usia 13-15 tahun di Makassar lebih banyak terjadi pada laki-laki dan semua terdapat pada rahang atas. Secara klinis kebanyakan kasus ditemukan single supernumerary teeth dan pada beberapa kasus merupakan mesiodens, dengan bentuk morfologi conical paling banyak ditemukan.
\end{abstract}

Kata kunci: supernumerary teeth, anak usia 13-15 tahun, mesiodens

Koresponden: Asmawati. E-mail: asmaamin68@yahoo.com

\section{PENDAHULUAN}

Dalam dunia kedokteran gigi sering ditemukan kelainan pada gigi dalam rongga mulut. Kelainan pada gigi disebabkan karena gangguan pertumbuhan yang akan mempengaruhi struktur gigi dalam rongga mulut, namun tidak semua gangguan pertumbuhan menghasilkan keanekaragaman bentuk pada gigi dan tulang. Kelainan tersebut sering disebut anomali. Salah satu kelainan tersebut adalah supernumerary teeth atau jumlah gigi melebihi normal.
Supernumerary teeth atau gigi lebih merupakan suatu kelainan jumlah gigi berupa bertambahnya gigi dari jumlah normalnya dan dapat ditemukan di semua bagian lengkung gigi. Meskipun etiologinya belum diketahui pasti, untuk menjelaskan kondisi beberapa teori telah diajukan termasuk filogenetik, teori dikotomi, teori hiperaktif (hiperaktif dental lamina), gigi mengalami pembelahan pada tahap budstage, dan gabungan efek genetik dan lingkungan sebagaiman kecenderungan supernumerary teeth. ${ }^{1,2}$ 
Prevalensi supernumerary teeth pada gigi permanen telah dilakukan; dalam beberapa penelitian bervariasi $0,45-4,5 \%$. Di Irlandia bervariasi 2,2$3,7 \%$. Prevalensi supernumerary teeth 0,2-3,5\% dan lebih sering ditemukan pada gigi permanen dari pada gigi sulung. Frekuensi terjadi gigi lebih pada periode gigi sulung adalah $0,06-0,8 \%$.,3

Hasil penelitian yang dilakukan Dash mengenai supernumerary teeth di India menunjukkan prevalensi $0,65 \%$, sementara penelitian yang dilakukan Nasgari di Kawasan Selatan India, menunjukkan prevalensi supernumerary teeth $1,2 \%$.

Penelitian yang dilakukan Sharma dan Singh menunjukkan bahwa supernumerary teeth dideteksi dengan pemeriksaan klinis dan radiografi.Pada anak laki-laki lebih sering terjadi daripada perempuan dengan rasio 2,9:1. Single supernumerary terlihat pada $79 \%$ pasien, $20 \%$ untuk dua supernumerary dan $1 \%$ memiliki tiga atau lebih supernumerary teeth atau multiple supernumerary. ${ }^{5}$

Supernumerary teeth lebih sering terjadi pada rahang atas. Supernumerary teeth dapat dikategorikan dalam hal kronologi, topografi, dan morfologinya. Berdasarkan kronologis, supernumerary teeth dapat berkembang pada masa gigi sulung, masa gigi permanen, maupun pada masa gigi bercampur. Berdasarkan morfologinya, supernumerary teeth didefinisikan sebagai supplemental atau rudimentary (bentuk kerucut, tuberulate, odontome). Mesiodens, paramolar, distomolar dan parapremolar merupakan gambaran topografi dari supernumerary teeth. ${ }^{2}$

Supernumerary teeth bisa terjadi pada beberapa regio pada bagian rahang, misalnya regio antara, yaitu pada daerah insisivus depan atas yang disebut juga mesiodens. Mesiodens adalah supernumerary teeth yang berada pada rahang atas anterior dan berdekatan dengan sutura mid-line, dan antara gigi insisivus rahang atas. Selain mesiodens, biasanya terdapat supernumerary teeth di sebelah gigi molar yang disebut paramolar, di bagian paling belakang dari gigi molar terakhir disebut juga distomolar atau disebelah gigi premolar disebut parapremolars. ${ }^{1,6,12}$

Tujuan penelitian ini adalah untuk memperoleh gambaran umum mengenai karakteristik dan prevalensi supernumerary teeth pada anak usia 1315 tahun di Makassar. Dengan adanya prevalensi supernumerary teeth serta dampaknya yang besar terhadap letakgigi permanen dan estetik, maka perlu segera dipikirkan upaya preventif sedini mungkin.

\section{BAHAN DAN METODE}

Populasi penelitian dengan rancangan observasi deskriptif adalah seluruh siswa-siswi yang terdaftar di beberapa sekolah menengah pertama (SMP) yang telah ditetapkan. Berdasarkan perhitungan, diperoleh jumlah sampel 3.938 orang siswa dengan metode pengambilan sampel yang digunakan adalah multistage random sampling.

Data diperoleh dengan pemeriksaan langsung rongga mulut dengan menggunakan sonde dan kaca untuk melihat ada tidaknya supernumerary teeth dan melakukan wawancara pada tiap sampel yang memiliki supernumerary teeth.

\section{HASIL}

Penelitian ini dilakukan pada 3.938 orang siswa dengan 24 supernumerary teeth. Prevalensinya pada anak usia 13, 14 dan 15 tahun di Makassar didapatkan anomali supernumerary teeth 22 sampel $(0,6 \%)$ dan tidak terdapat anomali sebanyak 3916 sampel $(99,4 \%)$.

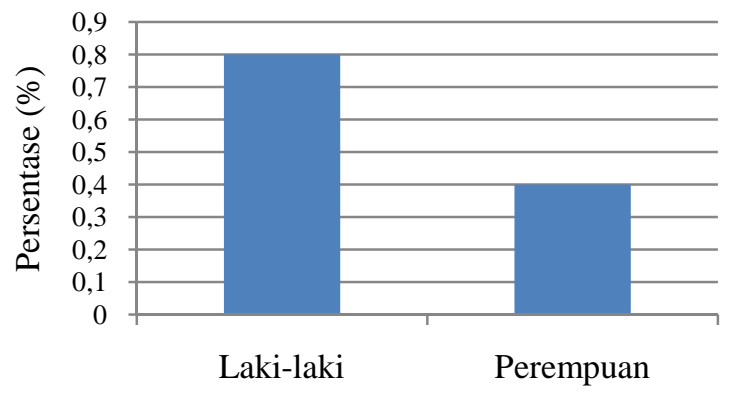

Jenis Kelamin

Gambar 1 Sampel yang mengalami supernumerary teeth berdasarkan jenis kelamin

Prevalensi supernumerary teeth berdasarkan jenis kelamin (Gambar 1) tampak dengan grafik batang; lebih banyak pada laki-laki yaitu 15 orang $(0,8 \%)$ sedangkan perempuan 7 orang $(0,4 \%)$.

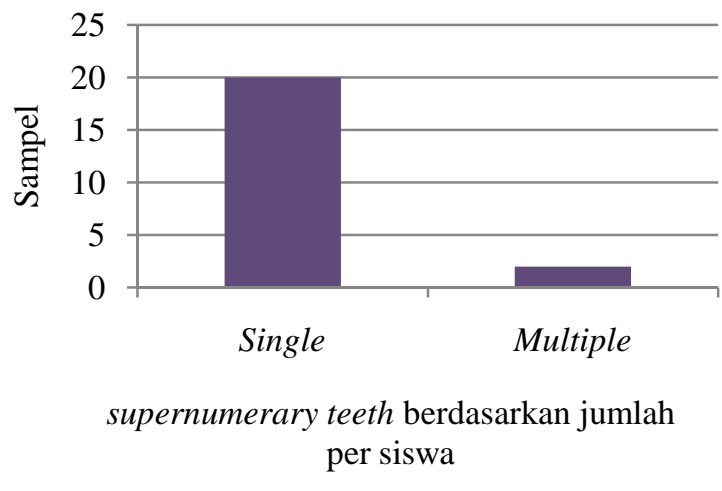

Gambar 2 Jumlah sampel dengan supernumerary teeth berdasarkan jumlah pada setiap orang

Grafik Gambar 2 memperlihatkan, prevalensi supernumerary teeth berdasarkan jumlahnya pada setiap orang. Single supernumerary teeth 20 orang $(90,9 \%)$, multiple supernumerary 2 orang $(9,1 \%)$. 
Pada Gambar 3 tampak prevalensi karakteristik sampel berdasarkan lokasi, yaitu mesiodens sebanyak $14(58,3 \%)$, lateral 10 sampel (41,7\%). Tidak ada lokasi pramolar, paramolar dan distomolar.

Prevalensi karakteristik supernumerary teeth berdasarkan status erupsi (Gambar 4); didapatkan 23 supernumerary teeth $(95,8 \%)$ yang erupsi sempurna dan hanya $1(4,2 \%)$ yang erupsi sebagian.

Sedangkan prevalensi karakteristik berdasarkan morfologinya, supernumeraryteeth berbentuk conical sebanyak 20 sampel $(83,4 \%)$, bentuk tubercular 2 sampel $(8,3 \%)$, bentuk supplementale $2(8,3 \%)$ dan bentuk odontoma tidak ada (Gambar 5).

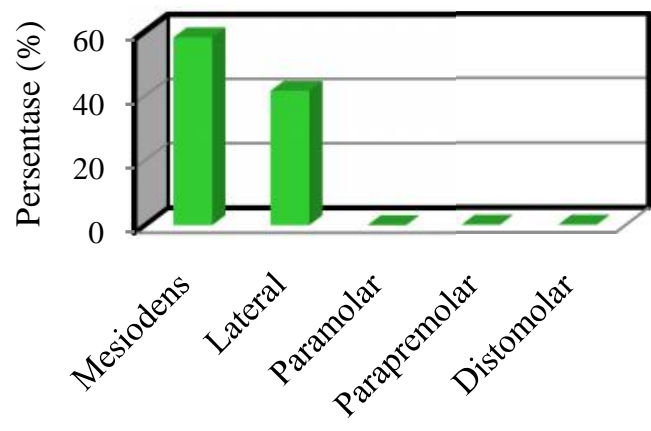

Lokasi Supernumerary Teeth

Gambar 3 Supernumerary teeth berdasarkan lokasinya

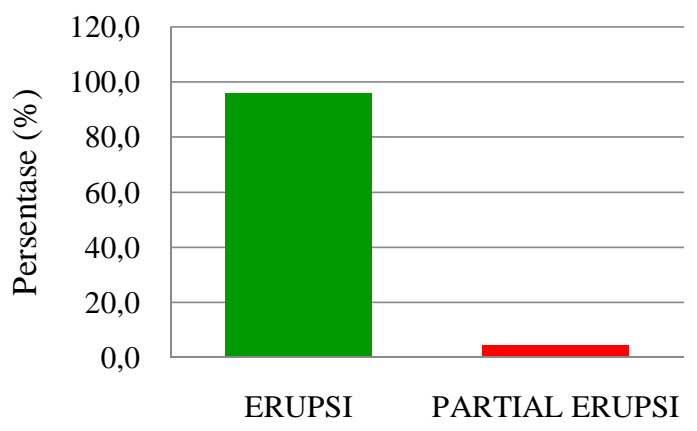

Status Erupsi

Gambar 4 Persentase sampel dengan supernumerary teeth berdasarkan status erupsi

\section{PEMBAHASAN}

Hasil pemeriksaan yang dilakukan pada anak usia 13-15 tahun di Makassar didapatkan 22 sampel $(0,6 \%)$ yang memiliki anomali supernumerary teeth yang semuanya terletak pada rahang atas. Hasil ini sesuai dengan penelitian Szkaradkiewics yang menunjukkan prevalensi supernumerary teeth pada periode gigi permanen bervariasi antara $0,1-6,9 \%{ }^{11}$ dan hasil penelitian Candirli bahwa supernumerary teeth sebesar 90-8\%\% pada rahang atas. ${ }^{7}$

Prevalensi supernumerary teeth lebih banyak pada laki-laki $(0,8 \%)$ sedangkan perempuan $(0,4 \%)$.
Hasil tersebut sesuai dengan penelitian Sharma, Sharman dan Singh, dan Dowling menunjukkan bahwa supernumerary teeth yang dideteksi dengan pemeriksaan klinis pada anak laki-laki lebih banyak dibandingkan perempuan. Hal ini sama dengan hasil penelitian Celikoglu yang menunjukkan bahwa supernumerary teeth yang terdeteksi pada 42 sampel (rasio 1,8:1) dan pada penelitian Kalyan, rasio 2:1. Hal ini disebabkan mungkin karena supernumerary teeth dihubungkan dengan gen resesif autosom, yang dapat berpenetrasi pada laki-laki, seperti yang disarankan oleh Niswander. Sedangkan Schmuckli dalam penelitiannya anak laki-laki lebih tinggi dari pada anak perempuan yakni 1,1:0,4., ${ }^{1,4,5,9-11}$

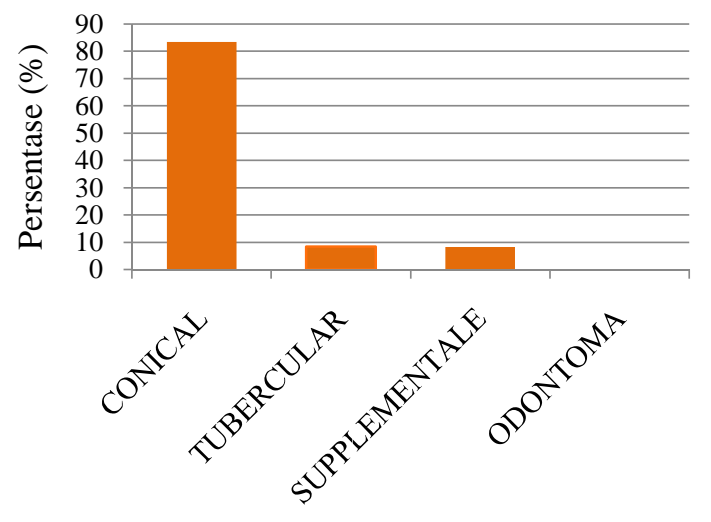

Keadaan Morfologi

Gambar 5 Persentase sampel dengan supernumerary teeth berdasarkan keadaan morfologi

Prevalensi supernumerary teeth berdasarkan jumlahnya pada setiap orang, ditemukan single supernumerary teeth pada 20 orang, sedangkan multiple supernumerary sebanyak 2 orang. Hal ini sesuai hasil penelitian dari Sharman dan Singh yang menyatakan bahwa prevalensi supernumerary teeth paling banyak hanya satu (79\%), sedangkan prevalensi sampel yang memiliki dua supernumerary teeth yaitu $20 \%$, dan $1 \%$ memiliki tiga atau lebih (multiple supernumerary).

Hal tersebut sama dengan hasil penelitian Celikoglu dkk menunjukkan prevalensi supernumerary teeth paling banyak hanya tunggal (75\%), lainnya memiliki dua supernumerary teeth yaitu $25 \%$. $^{1,5}$

Prevalensi karakteristik sampel berdasarkan lokasi, mesiodens sebanyak 14 sampel $(58,3 \%)$, lateral sebanyak 10 sampel $(41,7 \%)$. Sedangkan lokasi pramolar, paramolar dan distomolar tidak ada. Hal ini sama dengan hasil penelitian Celikoglu yang menunjukkan supernumerary teeth jenis mesiodens lebih banyak (31,3\%) dibandingkan jenis lateral $(22,9 \%)$. Pada penelitian Dowling berdasarkan catatan dari 100 pasien dengan supernumerary teeth 
pada gigi permanen, yang menghadiri kesehatan masyarakat klinik ortodontik menunjukkan sekitar 83\% dari supernumerary teeth gigi ditemukan di daerah anterior rahang atas. ${ }^{5,11}$

Pada penelitian Schmuckli, prevalensi anak laki-laki lebih tinggi daripada perempuan $(1,1: 0,4)$, proporsi terbesar supernumerary teeth ditemukan di daerah anterior rahang atas (38 dari 44 gigi, 86\%). ${ }^{9}$

Prevalensi karakteristik supernumerary teeth berdasarkan status erupsi, 95,8\% erupsi sempurna dan hanya $1(4,2 \%)$ yang erupsi sebagian.

Prevalensi karakteristik berdasarkan bentuknya, bentuk conical 20 sampel $(83,4 \%)$, bentuk tubercular 2 sampel (8,3\%), bentuk supplementale 2 sampel $(8,3 \%)$ dan bentuk morfologi odontoma tidak ada. Hal ini sesuai dengan hasil penelitian Schmuckli bahwa jenis bentuk supernumerary teeth $70 \%$ conical, $25 \%$ supplemental dan 5\% tuberculate. ${ }^{7}$

Berdasarkan hasil penelitian yang dilakukan pada 14 SMP, di Makassar disimpulkan bahwa prevalensi supernumerary teeth pada anak pada anak usia 13-15 tahun di Makassar sebanyak 0,6\% yang semuanya terdapat pada rahang atas. Prevalensi kejadiannya lebih banyak pada laki-laki (2:1). Berdasarkan jumlahnya, single supernumerary teeth $(90,9 \%)$ dan multiple supernumerary teeth $(9,1 \%)$. Berdasarkan lokasi supernumerary teeth, mesiodens $(58,3 \%)$, dan lateral $(41,7 \%)$.

Berdasarkan status erupsinya, 95,8\% erupsi sempurna dan $4,2 \%$ yang erupsi sebagian. Sedangkan berdasarkan bentuknya, conical $(83,4 \%)$, bentuk tubercular $(8,3 \%)$, bentuk supplementale $(8,3 \%)$.

Berdasarkan hal tersebut, perlu dilakukan penyuluhan mengenai pemahaman supernumerary teeth, karakteristik dan penanganannya berdasarkan pemeriksaan klinis dan wawancara. Tindakan yang tepat menghindarkan atau mengurangi kemungkinan komplikasi. Untuk itu, diperlukan penelitian lebih luas sehingga diketahui prevalensi supernumerary teeth di Makassar.

\section{DAFTAR PUSTAKA}

1. Sharma A, Singh VP. Supenumerary teeth in Indian children: a survey of 300 cases. Int J Dent 2012; 10.

2. Yassaei S, Mahdjoube GM. Late developing supernumerary premolars: Reports of two cases. Int J Dent 2013

3. Primaywati H, Suwelo IS. Manajemen gigi lebih pada periode gigi sulung. M.I Kedokteran Gigi 2008; 23(10)

4. Kalyan DK, Saraswathy KG. An epidemiological study on supernumerary teeth: a survey on 5000 people. J Clin Diagn 2013; 7.

5. Celikoglu M, Kamak H, Husamettin O. Prevalence and characteristics of supernumerary teeth in a non-syndrome Turkish population:Associated pathologies and proposed treatment.Med Oral Patol Oral Cir Bucal 2010;15(4):e575-8

6. Meighani G, Pakdaman. Diagnosis and management of supernumerary (mesiodens) a review of the literature. J Dent Tehran University 2010; 7(1): 11.

7. Candirli C, Dayisoylu E. Prevalence and characteristics of supernumerary teeth in east-northern Turkish population. Cumhuriyet Dent J 2012; 15(4):335-9

8. Kapdan A, Kustarci A. Dental anomalies in the primary dentition of Turkish children. Eur J Dent 2012; 6(2):178-83

9. Schmuckli R, Lipowsky C. Prevalence and morphology of supernumerary teeth in the population of a Swiss community. Shwiez Monatsschr Zahnmed 2010; 120:987-990

10. Sapp JP,Eversole LR,Wysocky GP.Contemprary oral and maxillofacial pathology. ${ }^{\text {nd }}$ Ed.Missouri:Mosby;2004.p.2-7.

11. Szkaradkiewicz AK, Karpinski TM. Supernumerary teeth in clinical practice. J Biol Earth Sci 2011; 1(1):M1-M5

12. Mangalekar SB, Tajjamul A. Molariform mesiodens in primary dentition. Int J Dent 2013; 3.

13. Sharma A, Singh VP. Dentigerous cyst associated with unusual supernumerary teeth:A case report. AJMS 2011:124-7

14. Dowling O. Supernumerary teeth among Irish school children attending the public orthodontic service in Cork and Kerry. J Irish Dent Assoc 2009: 55(1): 35-7

15. Cakan U, Erdem NF. Management of a non-syndromic case of maxillary and mandibular supernumerary teeth: a clinical report. ISPUB 2011; 10(1).

16. Parolia A, Kundabala M. Management of supernumerary teeth. J Conserv Dent 2011; 14(3): 221-4

17. Sudiono J. Gangguan tumbuh kembang dentokraniofasial. Jakarta: EGC; 2008. hal. 23-6

18. McDonal RE, Avery DR, Dean JA. Dentistry for the child and adolescent $8^{\text {th }}$ Ed. Missouri: Mosby; 2004.p. 665-8

19. Inchingolo F, Tatullo M. Non-syndromic multiple supernumerary teeth in a family unit with a normal karyotype: case report. Int J Med Sci 2010; 7(6): 378-84

20. Padro EF, Armengol JP. A descriptive study of 113 unerupted supernumerary teeth in 79 pediatric patient in Barcelona. Med Oral Patol Oral Cir Bucal 2009;14(3): E146-52

21. Diaz A, Orozco J, Fonseca M. Multiple hyperodontia: report of a case with 17 supernumerary teeth with non syndromic association. Med Oral Patol Oral Cir Bucal 2009; 14(5):E229-31

22. Parihar A, Kishore R. Multiple impacted permanent and supernumerary teeth:a case report. J Clin Diagn Res 2010; (4):3287-8

23. Scheiner MA, Sampson WJ. Supernumerary teeth: a review of the literature and four case reports. Aust Dent J 2007;42(3): 13

24. Wray DD, Stenhouse, Clark AJE. Textbook of general and oral surgery. St Louis:Churchill Livingstone; 2003.p.254-5 